\title{
A PLASTIC DAMAGE CONSTITUTIVE MODEL FOR COMPOSITE MATERIALS
}

\author{
S. OLLER, E. OÑATE, J. MIQUEL and S. BOTELLO \\ Universitat Politècnica de Catalunya, E.T.S. Ingenieros de Caminos, Canales y Puertos 08034, \\ Barcelona, Spain
}

(Received 5 May 1994; in revised form 13 July 1995)

\begin{abstract}
In this paper a generalized elasto-plastic damage model for the analysis of multiphase frictional composite materials is presented. Details of the derivation of the secant and tangent constitutive equations are given. Mixing theory is used to insert the basic constitutive expressions for each substance on the multiphase composite solid. Details of the numerical implementation of the model into a general non-linear finite element solution scheme are presented. Some examples of linear and non-linear behaviour of composites are given. Copyright $\mathbb{C} 1996$ Elsevier Science Ltd.
\end{abstract}

\section{NOMENCLATURE}

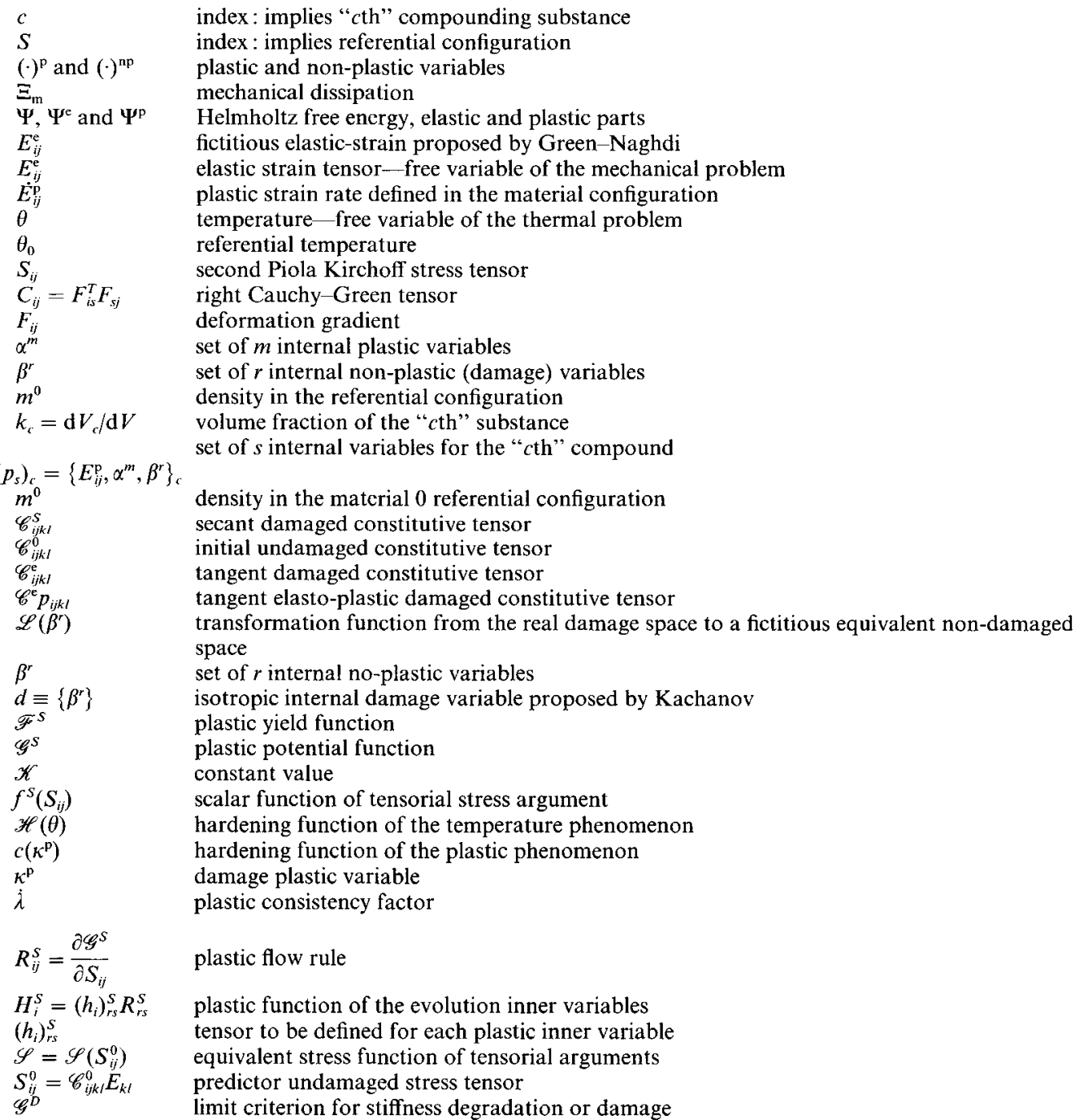




$\begin{array}{ll}g(\mathscr{S}) & \text { the damage function } \\ g\left(\beta^{r}\right) \equiv g\left(\mathscr{S}^{r}\left(\beta^{r}\right)\right) & \text { threshold damage level } \\ \mathscr{S}^{r}\left(\beta^{r}\right) & \text { scalar function of uniaxial strength, interpreted as a damage hardening function } \\ \dot{\mu} & \text { damage consistency factor } \\ b_{i}^{S} \text { and } b_{i} & \text { referential and current configuration body loads } \\ t_{i}^{S} \text { and } t_{i} & \text { referential and current configuration surface loads } \\ V^{S} & \text { referential volume } \\ \mathscr{S}^{S} & \text { referential surface where the acting traction loads } \\ J=\left\|F_{i j}\right\| & \text { jacobian determinant } \\ \alpha_{i j}^{\theta} & \text { thermal dilatancy tensor } \\ F_{\text {resid }} & \text { residual forces } \\ F_{\text {ext }} & \text { external forces } \\ G_{f} & \text { maximum dissipate fracture energy } \\ f^{\text {Comp }} & \text { maximum compression strength at the yield limit } \\ f_{\text {Pamp }}^{\text {Comp }} & \text { maximum compression strength at the peak limit } \\ f_{\text {Peak }}^{\text {Comp }} & \text { maximum compression strain at the peak limit } \\ E & \text { initial young module. }\end{array}$

\section{INTRODUCTION}

Bulk composite materials and those materials composed by a matrix with short fibres (whiskers) and/or long oriented fibres, typical in laminate composites, have a global physical behaviour influenced by the mechanical characteristic of each simple compounding and by its topology (Rouvray and Haug, 1989; (Pickett et al., 1989). Several phenomena such as their anisotropy with directional irrecoverable strains, micro-cracking, loss of the stiffness and rheological behaviour occur over each simple compounding irrespectibly if this is of bulk or fibre kind. Besides the influence of these phenomena, other effects are produced in the compoundings interfaces due to the loss of kinematic compatibility. This leads to a loss of integrity in the whole composite (typically named delamination phenomenon). This loss

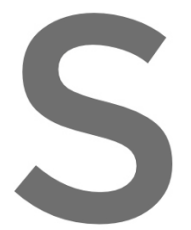
of kinematic compatib fibre matrix debondi phenomena induce $a$ loss of globalstrength. as the sum of the contribution from each compounding $p$

Micro and macro-models are the two alternatives to study the mechanical behaviour

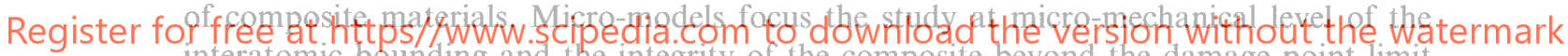
interatomic bounding and the integrity of the composite beyond the damage point limit (Obraztsov and Vasilev, 1982). Although micro-models are quite expensive for practical purposes they can be successfully used in the modelling of composite material behaviour. Macro-mechanical models express the whole composite constitutive behaviour as that of a single material. This information can only be achieved by means of experimental analyses.

Most existing macro-mechanical models are based on mixing materials theory. This allows the study of the composite mechanical behaviour as a combination of several single compoundings, satisfying an appropriate closing equation. This equation establishes the inter-material kinematic conditions and in the simplest case, chosen in this work, it assumes perfect compatibility between the different compoundings. The closing equation can include more complex inter-material phenomena as delamination, debonding or any other kinematic behaviour. Although this equation is an important condition of each mixing theory it does not change the basic principles establishing for the theory of the interaction between the compounding substances.

In this paper a macro-model adequate for analysis of the non-linear mechanical response of composite materials is presented. The model is based on the mixture of the basic substances of the composite and it allows the evaluation of the inter-dependence between the constitutive behaviour of the different compounding materials. The behaviour of each compound is modelled by a general elasto-plastic damage model, termed here "base model", adequate for analysis of metals and geomaterials. The different base models for each compound are combined using mixing theory to simulate the behaviour of the composite multiphase material.

Mixing theory is very adequate to explain the behaviour of a composite solid. This theory is based on the principle of interaction of the compounding substances with the 
following assumptions: (i) each infinitesimal volume of a composite is filled by a finite number of compounding substances; (ii) each compound participates in the behaviour of the composite in the same volume proportion; (iii) all compounds are subjected to the same strains (closing equation or compatibility concept) and (iv) the volume occupied by each compound is much smaller than the total volume of the composite. Assumption (ii) implies an homogeneous distribution of all compounds in a certain region of the composite. The interaction between the different compounds, each one defined by an appropriate constitutive law, yields the overall constitutive behaviour of the composite in terms of the percentage volume occupied by each compound and its distribution within the composite.

Mixing theory was studied in detail by Trusdell and Toupin (1960) and a few years later by Green and Naghdi (1965). Years later Ortiz and Popov (1982) used mixing theory to propose a two phase model for analysis of concrete.

In this paper mixing theory is used to propose a non-linear constitutive model for multiphase composite materials. Each phase can have a general anisotropic behaviour defined by means of an equivalent isotropic model recently proposed by the authors (Oller et al., 1995). For simplicity only isotropic single phases are treated in this paper. Also, each phase can act as the matrix part of the composite, or else as short or long reinforcing fibres.

The layout of the paper is the following. In the next section the basis of the isotropic elasto-plastic model for each of the individual compounding substances is presented. Details of the mixing theory used to reproduce the overall behaviour of the composite are given next. The algorithm for numerical implementation of the model within a non-linear finite element solution scheme is then detailed. Finally, some examples of application to the linear and non-linear analysis of composites are given.
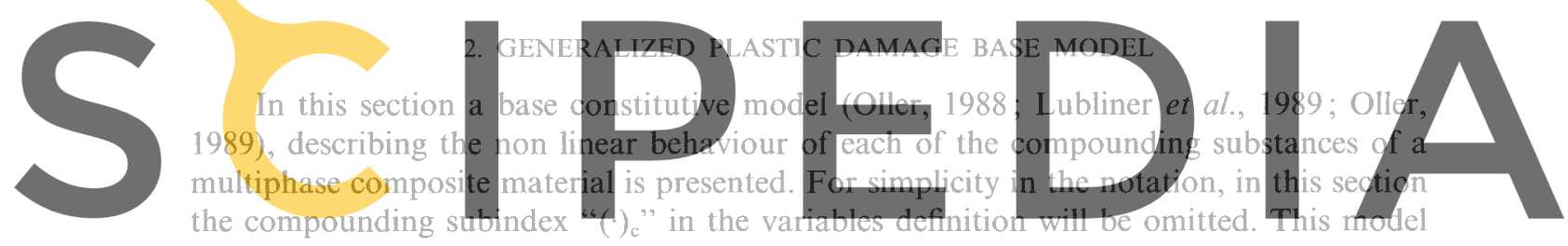
will be used in conjunction with mixing theory to derive the overall constitutive equation

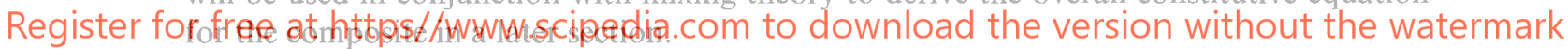

The base model uses plastic damage theory and it is formulated in a material con-

figuration using total Lagrangian kinematics. The model is adequate to treat problems with large plastic strains and small elastic strains (Lubliner et al., 1989; Oller, 1989). Weak thermal-mechanical coupling is assumed and therefore only stable thermal states can be treated. The model as presented here can simulate the behaviour of metallic and ceramic materials and geomaterials.

The secant constitutive equation and the mechanical dissipation for an uncoupled thermo-mechanical problem is obtained in the standard manner (via Clasius-Planck inequality (Malvern, 1969; Lubliner, 1972; (Lubliner, 1985), as :

$$
\begin{gathered}
S_{i j}=m^{0} \frac{\partial \Psi\left(E_{i j}^{\mathrm{e}}, \theta, \alpha^{m}, \beta^{r}\right)}{\partial E_{i j}^{\mathrm{e}}} \\
\Xi_{\mathrm{m}}=\Xi_{\mathrm{m}}^{\mathrm{p}}+\Xi_{\mathrm{m}}^{\mathrm{np}}=\underbrace{\frac{S_{i j} \dot{E}_{i j}^{\mathrm{p}}}{m^{0}}-\frac{\partial \Psi}{\partial \alpha^{m}} \dot{\alpha}^{m}}_{\Xi_{\mathrm{m}}^{\mathrm{p}}}-\underbrace{\frac{\partial \Psi}{\partial \beta^{r}} \dot{\beta}^{r}}_{\Xi_{\mathrm{m}}^{\mathrm{np}}} \geqslant 0
\end{gathered}
$$

In eqn (2) $(\cdot)^{\mathrm{p}}$ and $(\cdot)^{\mathrm{np}}$ denote the plastic and non-plastic contributions to the mechanical dissipation $\Xi_{\mathrm{m}}, \Psi$ is the free energy, $E_{i j}^{\mathrm{c}}$ is the elastic strain taken as the free variable of the mechanical problem, $\theta$ is the temperature as a free variable of the thermal problem, $S_{i j}$ is the second Piola Kirchoff stress tensor, $\alpha^{m}$ is the set of $m$ internal plastic variables, $\beta^{r}$ 
is the set of $r$ internal non-plastic (damage) variables, and $m^{0}$ is the density in the material configuration.

\subsection{Free energy and Green-Naghdi strain tensor}

As already mentioned, the base model is formulated in a material configuration for thermally stable problems (i.e. with zero temporal changes of temperatures) and using the concept of uncoupled elasticity from Green-Naghdi theory (Green and Naghdi, 1964; Lubliner, 1972 ; Lubliner, 1990 ; García Garino and Oliver, 1992). Under these assumptions the free energy can be written as the sum of two independent elastic and plastic contributions, i.e.

$$
\Psi\left(E_{i j}^{\mathrm{e}}, \theta, \alpha^{m}, \beta^{r}\right)=\Psi^{\mathrm{e}}\left(E_{i j}^{\mathrm{e}}, \theta, \beta^{r}\right)+\Psi^{\mathrm{p}}\left(\alpha^{m}, \theta\right) .
$$

The elastic free energy is assumed to be a scalar quadratic function of the form:

$$
\Psi^{\mathrm{e}}\left(E_{i j}^{\mathrm{e}}, \theta, \beta^{r}\right)=\frac{1}{2 m_{0}} E_{i j}^{\mathrm{e}} \mathscr{C}_{i j k l}^{\mathrm{s}}\left(\beta^{r}, \theta\right) E_{k l}^{\mathrm{e}}
$$

where the elastic strain tensor $E_{i j}^{\mathrm{e}}$ coincides with the fictitious elastic strain proposed by Green-Naghdi (Green and Naghdi, 1964; Lubliner, 1990), and it is obtained as the difference between the total and plastic Lagrangean strains, i.e.
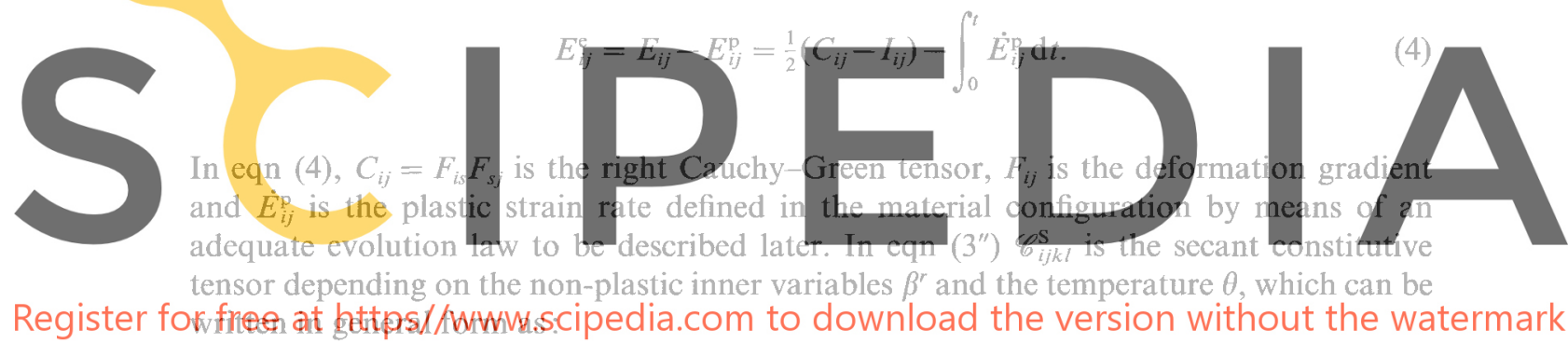

$$
\mathscr{C}_{i j k l}^{\mathrm{s}}\left(\beta^{r}, \theta\right)=\mathscr{L}\left(\beta^{r}\right) \mathscr{C}_{i j k l}^{\mathrm{0}}(\theta)
$$

where $\mathscr{C}_{i j k l}^{0}=\lambda^{\mathrm{L}}(\theta) \cdot \delta_{i j} \delta_{k l}+\mu^{\mathrm{L}}(\theta) \cdot\left(\delta_{i k} \delta_{j l}+\delta_{i l} \delta_{j l}\right)$ is the initial elastic stiffness of the undamaged material, $\lambda^{\mathrm{L}}$ and $\mu^{\mathrm{L}}$ are the Lamé coefficients and $\mathscr{L}\left(\beta^{r}\right)$ is a transformation function from the real damage space to a fictitious equivalent non-damaged one (Oller, 1989). The simplest expression for $\mathscr{L}\left(\beta^{r}\right)$ coincides with the isotropic form proposed by Kachanov (1958) as $\mathscr{L}\left(\beta^{r}\right)=(1-d)_{r=1}$, and in this case $d \equiv\left\{\beta^{r}\right\}$. Note that superindex $S$ denotes hereafter variables in the damaged material configuration.

\subsection{Yield and plastic potential functions}

The yield and the plastic potential functions are expressed in the material configuration as :

$$
\mathscr{F}^{\mathrm{S}}\left(S_{i j}, \alpha^{m}, \theta\right)=0 ; \quad \mathscr{G}^{\mathrm{S}}\left(S_{i j}, \alpha^{m}, \theta\right)=\mathscr{K}
$$

where $\mathscr{K}$ is a constant value. In order to preserve the physical meaning of cohesion it is required that both functions be a first degree homogeneous function of $S_{i j}$. Examples of yield functions satisfying this condition are the standard Von-Mises or Tresca functions for metals (Malvern, 1969; Lubliner, 1990) and those of Mohr-Coulomb, Drucker-Prager and Lubliner (Oller, 1988; Lubliner et al., 1989), for geomaterials. In all cases the temperature acts as the strain hardening function in the following form: 


$$
\mathscr{F}^{\mathrm{s}}\left(S_{i j}, \alpha^{m}, \theta\right)=f^{\mathrm{s}}\left(S_{i j}\right)-\mathscr{H}(\theta) c\left(\kappa^{\mathrm{p}}\right)=0
$$

where $0 \leqslant \mathscr{H}(\theta) \leqslant 1$ is a temperature function equal to zero for materials at fusion state and to 1 for room temperature, $c\left(\kappa^{\mathrm{p}}\right)$ is the hardening function, and $\kappa^{\mathrm{p}}$ is the damage plastic variable that in this case is the unique element of the $\alpha^{m}$ set of $m=1$ internal plastic variables. More details about these variables can be seen in the following specifics papers: (Oller, 1988; Oñate et al., 1988; Lubliner et al., 1989; Oller, 1989; Oller et al., 1990).

\subsection{Evolution law for the plastic inner variables}

The flow rule is defined in the standard Green-Naghdi form for plastic models defined in the material configuration (Lubliner, 1984; Lubliner, 1986). This definition has been extended to the evolution laws of the plastic inner variables, as:

$$
\begin{aligned}
& \dot{E}_{i j}^{\mathrm{p}}=\dot{\lambda} R_{i j}^{\mathrm{S}}\left(S_{r s}, \alpha^{m}\right)=\dot{\lambda} \frac{\partial \mathscr{G}^{\mathrm{S}}}{\partial S_{i j}} \\
& \dot{\alpha}_{i}^{m}=\dot{\lambda} H_{i}^{\mathrm{s}}\left(S_{q l}, \alpha^{m}, G_{\mathrm{f}}\right)=\dot{\lambda}\left[\left(h_{i}\right)_{r s}^{\mathrm{s}}\left(S_{q l}, \alpha^{m}, G_{\mathrm{f}}\right) \cdot R_{r s}^{\mathrm{s}}\left(S_{q l}, \alpha^{m}\right)\right]
\end{aligned}
$$

where $\lambda$ is obtained from the plastic consistency condition, $\left(h_{i}\right)_{r s}^{\mathrm{S}}$ is a tensor to be defined for each plastic inner variable (Oller, 1989; Lubliner et al., 1989) and $G_{\mathrm{f}}$ is the maximum dissipate fracture energy (Lubliner et al., 1989; Oller et al., 1990).

\subsection{Limit criterion for stiffness degradation or damage}

An equivalent stress function is defined in the non-damage Piola-Kirchoff stress space,
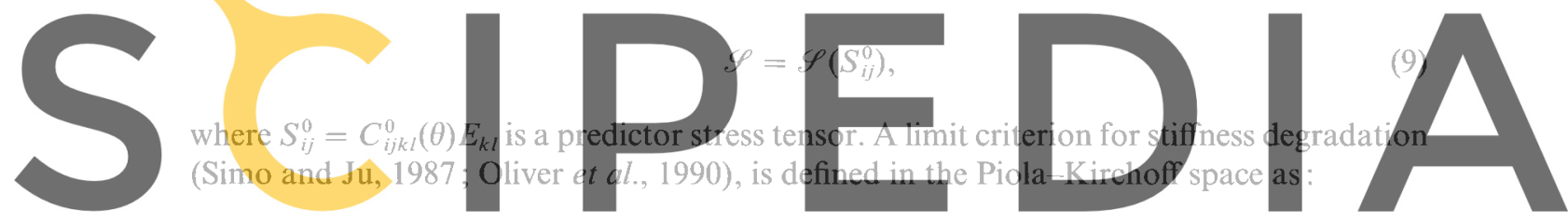

$$
\mathscr{S}-\mathscr{P}^{r}\left(\beta^{r}\right)=0 \quad \text { or } \quad \mathscr{G}^{\mathrm{D}}\left(\mathscr{S}, \beta^{r}\right)=g(\mathscr{S})-g\left(\beta^{r}\right)=0
$$

where $g(\cdot)$ is a scalar positive function with positive derivative. In this particular case $g(\mathscr{P})$ defines the damage function and $g\left(\beta^{r}\right) \equiv g\left(\mathscr{P}^{r}\left(\beta^{r}\right)\right)$ is the threshold damage level as a function of the uniaxial strength $\mathscr{S}^{r}\left(\beta^{r}\right)$ which can be interpreted as a damage hardening function.

\subsection{Evolution law for damage inner variables}

The evolution law for the non-plastic inner variables $\beta^{r}$ has the following form:

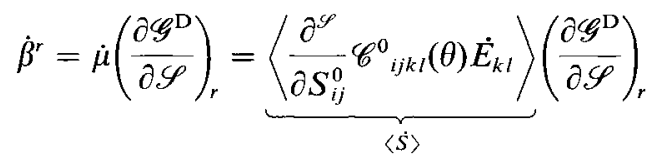

where $\dot{\mu}$ is obtained from the damage consistency condition* expressed as $\dot{\mathscr{G}}^{\mathrm{D}}=0$.

* The damage consistency condition (Bažant and Kim 1979), is defined by the following expression :

$$
\dot{\mathscr{G}}^{\mathrm{D}}=\frac{\partial g}{\partial \mathscr{S}^{\prime}} \dot{\mathscr{P}}-\frac{\partial g}{\partial \mathscr{S}^{r}} \underbrace{\frac{\partial \mathscr{P}^{r}}{\partial \beta^{r}} \dot{\beta}^{r}}_{\dot{\mathscr{S}}}=0 .
$$

Making use of the limit criterion of stiffness degradation [eqn (10)], in the last expression, result :

$$
\dot{\mathscr{S}}=\dot{\mathscr{S}} r=\dot{\mu}=\frac{\partial \mathscr{S}}{\partial S_{i j}^{0}} \dot{S}_{i j}^{0}=\frac{\partial \mathscr{S}}{\partial S_{i j}^{0}} \mathscr{C}_{i j k l}^{0}(\theta) \dot{E}_{k l} .
$$




\subsection{Secant constitutive equation}

Substituting into eqn (1) the expression of the free energy formulated in eqn (3), the secant constitutive equation (Oller, 1988; Oller, 1989; Lubliner et al., 1989), is obtained as :

$$
S_{i j}=\mathscr{C}_{i j k l}^{S}\left(\beta^{r}, \theta\right) E_{k l}^{e}=\overline{\mathscr{L}}\left(\beta^{r}\right) \mathscr{C}_{i j k l}^{0}(\theta) E_{k l}^{e}
$$

where $E_{i j}^{\mathrm{e}}=E_{i j}-E_{i j}^{\mathrm{p}}$ is the fictitious elastic strain tensor already mentioned.

\subsection{Tangent constitutive equation}

For stable thermal states, the temporal derivative of eqn (12) leads to:

$$
\begin{aligned}
& \dot{S}_{i j}=\dot{\mathscr{C}}_{i j k l}^{\mathrm{S}}\left(\beta^{r}, \theta\right) E_{k l}^{\mathrm{e}}+\mathscr{C}_{i j k l}^{\mathrm{S}}\left(\beta^{r}, \theta\right) \dot{E}_{k l}^{\mathrm{e}} \\
& =\left[\sum_{r} \frac{\partial \mathscr{C}_{i j k l}^{\mathrm{s}}\left(\beta^{r}, \theta\right)}{\partial \beta^{r}} \dot{\beta}^{r}+\sum_{r} \frac{\partial \mathscr{C}_{i j k l}^{\mathrm{s}}\left(\beta^{r}, \theta\right)}{\partial \theta} \dot{\theta}\right] E_{k l}^{\mathrm{e}} \\
& \mathscr{L}\left(\beta^{r}\right) \mathscr{F}_{i j k i}^{\theta}(\theta) \quad=0 \text { thermal stable process } \\
& +\mathscr{C}_{i j k l}^{\mathrm{s}}\left(\beta^{r}, \theta\right)\left(\dot{E}_{k l}-\dot{E}_{k l}^{p}\right)
\end{aligned}
$$

and using eqns (5) and (12), results:
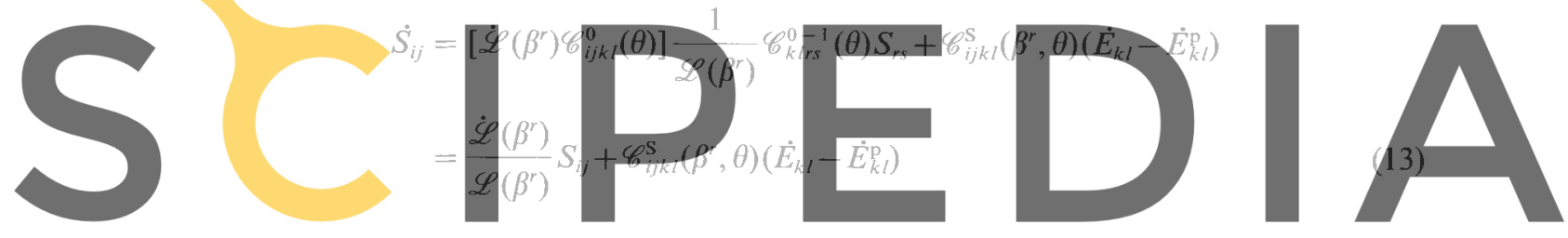

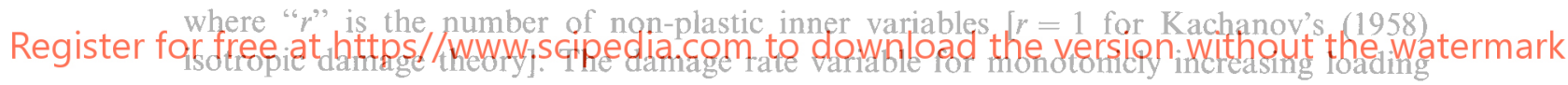

can be written from eqn (11) as:

$$
\dot{\mathscr{L}}\left(\beta^{r}\right)=\sum_{r} \frac{\partial \mathscr{L}\left(\beta^{r}\right)}{\partial \beta^{r}} \dot{\beta}^{r}=\underbrace{\left[\sum_{r} \frac{\partial \mathscr{L}\left(\beta^{r}\right)}{\partial \beta^{r}}\left(\frac{\partial \mathscr{G}^{D}}{\partial \mathscr{S}}\right)_{r} \frac{\partial \mathscr{S}}{\partial S_{i j}^{0}} \mathscr{C}_{i j k l}^{0}(\theta)\right]}_{T_{k l}} \dot{E}_{k l} .
$$

Substituting eqn (14) into eqn (13) the stress-strain rate relationship can be written as:

$$
\dot{S}_{i j}=\mathscr{C}_{i j k l}^{\mathrm{e}}\left(\beta^{r}, \theta\right) \dot{E}_{k l}-\mathscr{C}_{i j k l}^{\mathrm{s}}\left(\beta^{r}, \theta\right) \dot{E}_{k l}^{\mathrm{p}}
$$

where $\mathscr{C}_{i j k l}^{\mathrm{e}}\left(\beta^{r}, \theta\right)$ is given by:

$$
\mathscr{C}_{i j k l}^{\mathrm{e}}\left(\beta^{r}, \theta\right)=\mathscr{C}_{i j k l}^{\mathrm{S}}\left(\beta^{r}, \theta\right)+\frac{1}{\mathscr{L}\left(\beta^{r}\right)} T_{i j} S_{k l}
$$

Note that in eqn (15) the stress rates recover the standard form for $\mathscr{C}_{i j k l}^{\mathrm{e}} \equiv \mathscr{C}_{i j k l}^{\mathrm{s}}$. This equivalence occurs for undamaged states, i.e. when $\Sigma_{r} \partial \mathscr{L}\left(\beta^{r}\right) / \partial \beta^{r}=0$.

Using now the plastic consistency conditions $\dot{\mathscr{F}} \mathrm{s}=0$, and taking into account that the damage consistency condition $\dot{G}^{D}=0$ has already been imposed in eqn (11) to derive the parameter $\dot{\mu}$, the following rate constitutive equation is obtained : 


$$
\dot{S}_{i j}=\mathscr{C}_{i j k l}^{\mathrm{ep}}\left(\beta^{r}, \theta\right) \dot{\dot{E}_{k l}}
$$

where :

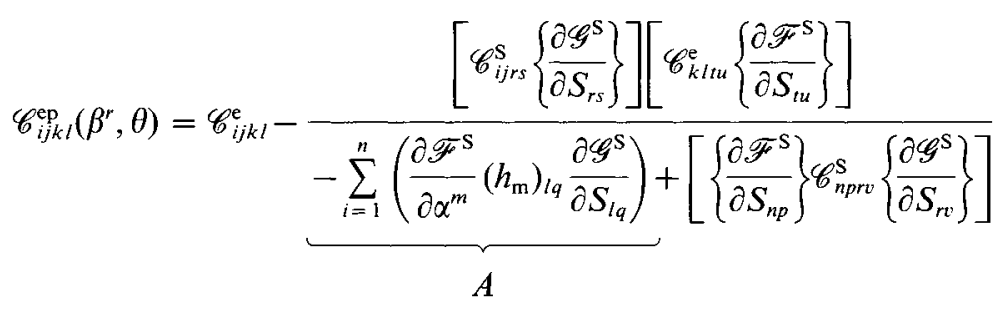

is the tangent elasto-plastic constitutive tensor, where $A$ is the plastic hardening parameter. It is deduced from eqn (16) that $\mathscr{C}_{i j k l}^{\mathrm{ep}}\left(\beta^{r}, \theta\right)$ is symmetric only when the following proportionality rule is satisfied (Lubliner, 1984; Oller, 1988; Lubliner et al., 1989) :

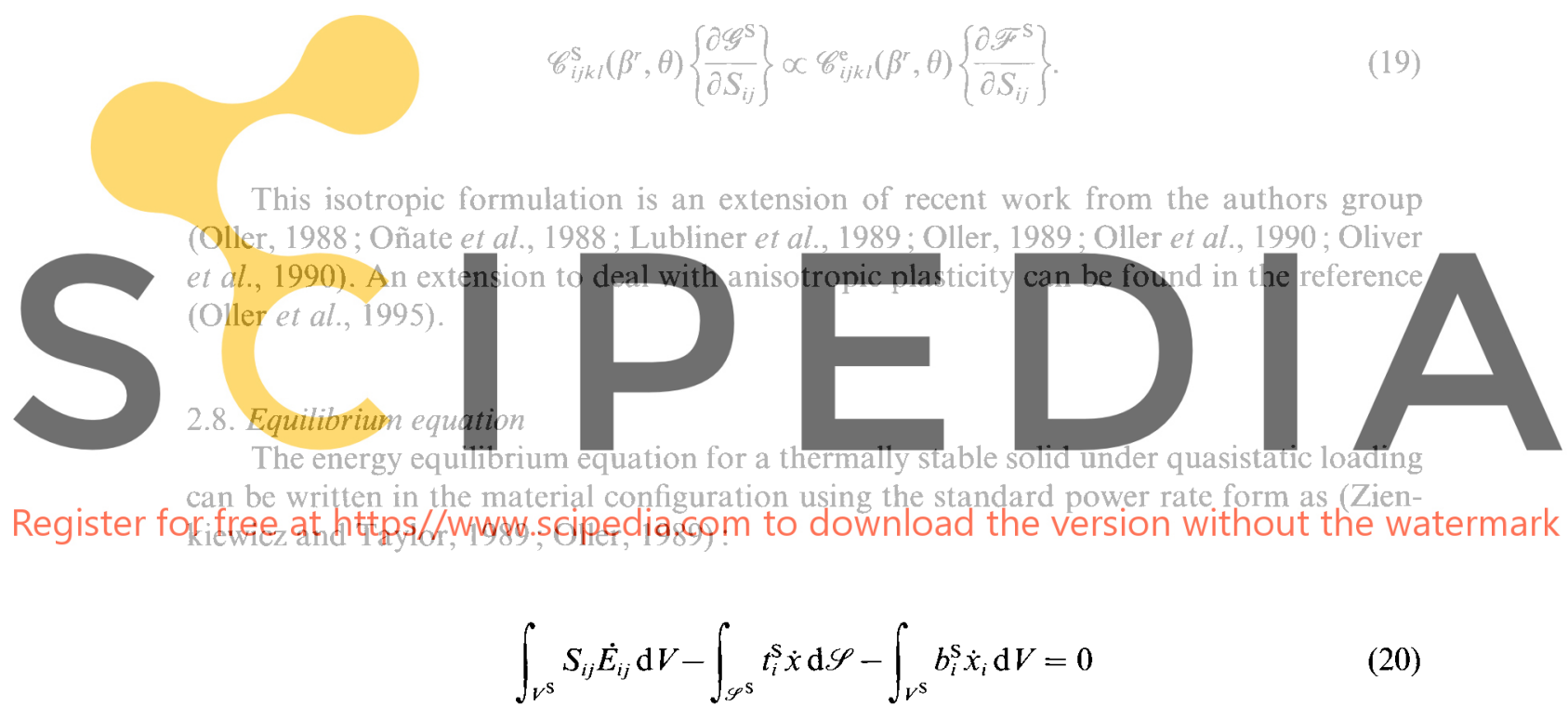

where $b_{i}^{\mathrm{S}}=J b_{i}$ and $t_{i}^{\mathrm{S}}=J t_{i}$ are body and surface loads acting over the volume $V$ and the surface $\mathscr{S}$ of the solid, respectively, $J=\left\|F_{i j}\right\|, F_{i j}$ is the deformation gradient and the current Piola-Kirchoff tensor stress is

$$
S_{i j}=\int_{0}^{t} \dot{S}_{i j} \mathrm{~d} t=\int_{0}^{t} \mathscr{C}_{i j k l}^{\mathrm{ep}}\left(\beta^{r}, \theta\right) \dot{E}_{k l} \mathrm{~d} t
$$

\section{CONSTITUTIVE MODEL BASED ON MIXING THEORY}

We present here a theory for modelling the interaction of compounding substances (Trusdell and Toupin, 1960; Green and Naghdi, 1965; Ortiz and Popov, 1982; Ortiz and Popov, 1982) of a multiphase material. This theory based on local continuum mechanics allows the consideration of the simultaneous combination of the different constitutive behaviours of each substance (i.e. elastic, elasto-plastic, elasto-brittle, elasto-damage, etc.). It is assumed here that the behaviour of each compounding substance follows precisely the 


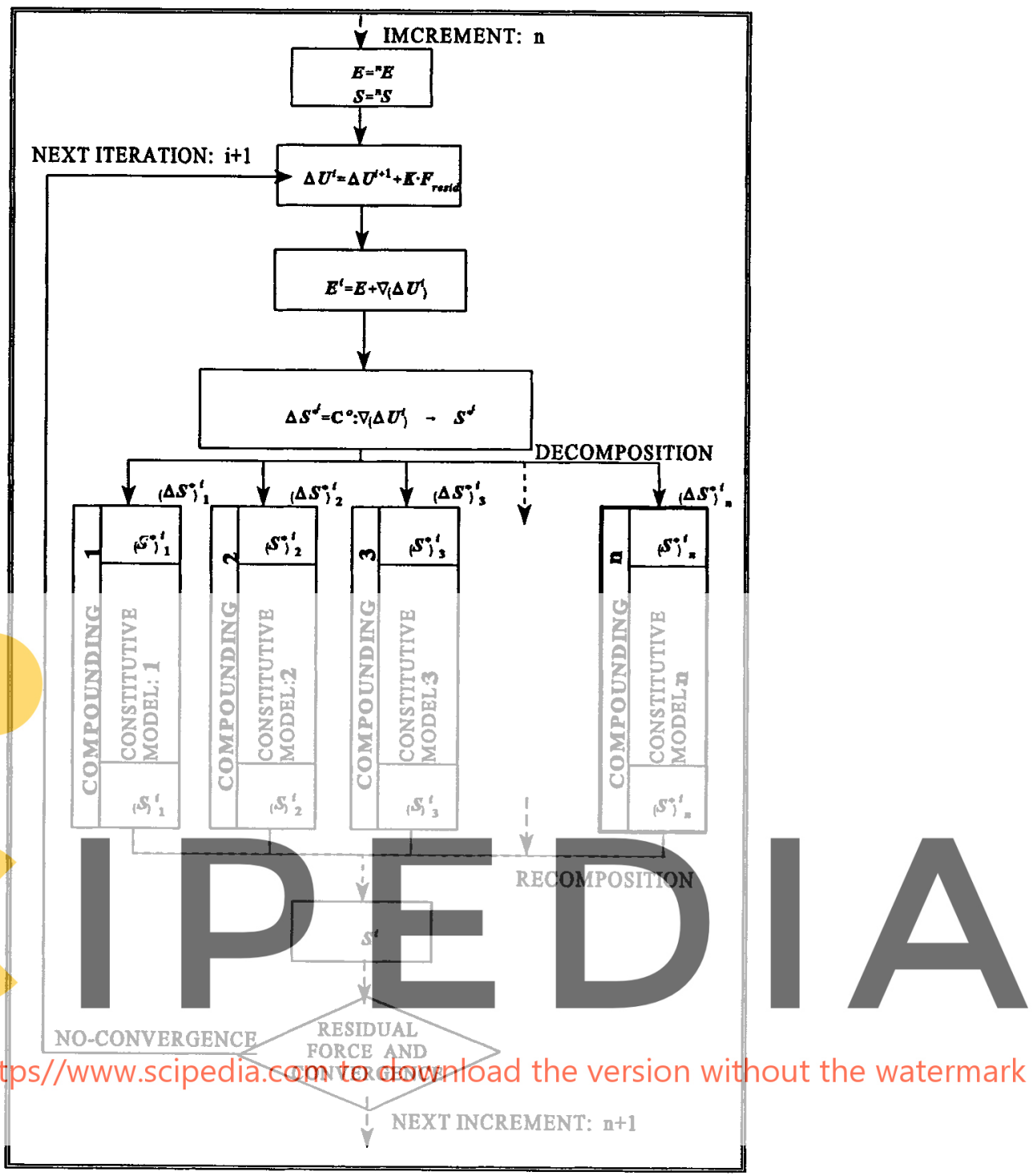

Fig. 1. Schematic flow diagram for non-linear solution of a multiphase material problem.

elasto-plastic damage material model previously described. However, other constitutive combinations are obviously possible (Fig. 1).

The simplest closing equation chosen in this work is based on the assumption of fully inter-compounding compatibility and the neglection of atomic diffusion (i.e. the temperatures are moderate), therefore the following strain compatibility is satisfied:

$$
\left(E_{i j}\right)_{1}=\left(E_{i j}\right)_{2}=\cdots=\left(E_{i j}\right)_{c}=\cdots=\left(E_{i j}\right)_{n} \equiv E_{i j} .
$$

In composite materials the free energy can be written as

$$
\Psi\left(E_{i j}^{\mathrm{e}}, \theta, \alpha^{m}, \beta^{r}\right)=\Psi(E_{i j}, \theta, \underbrace{E_{i j}^{\mathrm{p}}, \alpha^{m}, \beta^{r}}_{p_{s}})=\sum_{c=1}^{n} k_{c} \Psi_{c}\left(E_{i j}, \theta,\left(p_{s}\right)_{c}\right)
$$

where $\Psi_{c}\left(E_{i j}, \theta,\left(p_{s}\right)_{c}\right)$ is the free energy corresponding to each of the $n^{\text {th }}$ compounding substances in the mixture, $k_{c}=\mathrm{d} V_{c} / \mathrm{d} V$ is the volume fraction of that substance and $\left(p_{s}\right)_{c}$ is a set of inner variables for the " $c$ th" compound. Note that the following condition is satisfied: 


$$
\sum_{c=1}^{n} k_{c}=1
$$

which implies that for single phase materials the free energy expression of eqn (3) is recovered.

Following an identical procedure as for single-phase materials (Lubliner, 1985; Oller, 1988 ; Oller, 1989; Lubliner et al., 1989 ; Oñate et al., 1991), the secant constitutive equation for the whole composite is obtained from the Clasius-Planck inequality, i.e.

$$
S_{i j}=m^{0} \frac{\partial \Psi\left(E_{p q}, \theta, p_{r}\right)}{\partial E_{i j}}=m^{0} \sum_{c=1}^{n} k_{c} \frac{\partial \Psi_{c}\left(E_{p q}, \theta,\left(p_{r}\right)_{c}\right)}{\partial E_{i j}}=\sum_{c=1}^{n} k_{c}\left(S_{i j}\right)_{c}
$$

where $\left(S_{i j}\right)_{c}$ is the second Piola-Kirchoff stress tensor in the $c^{\text {th }}$ corresponding substance.

Also, from the Clausius-Planck inequality the following thermodynamic expression for the mechanical dissipation is obtained

$$
\frac{\partial \Psi\left(E_{p q}, \theta, p_{r}\right)}{\partial p_{i}} \dot{p}_{i}=\sum_{c=1}^{n} k_{c} \frac{\partial \Psi_{c}\left(E_{p q}, \theta,\left(p_{r}\right)_{c}\right)}{\partial\left(p_{i}\right)_{c}}\left(\dot{p}_{i}\right)_{c} \leqslant 0 .
$$

\section{composite material : \\ Tangent constitutive tensor}
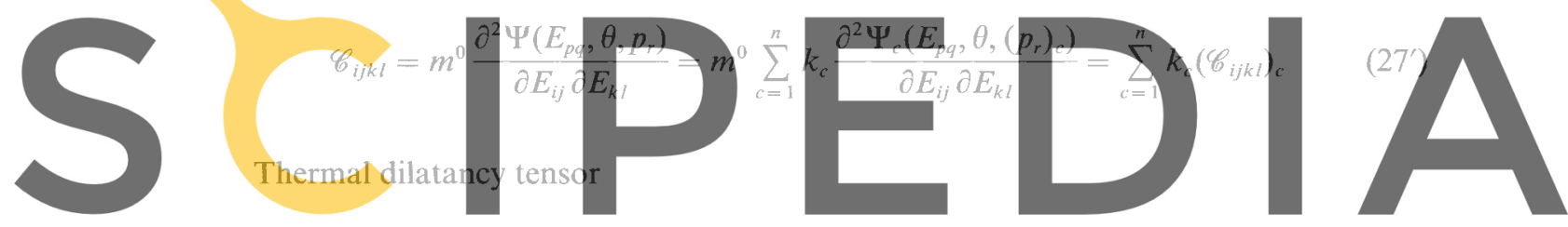

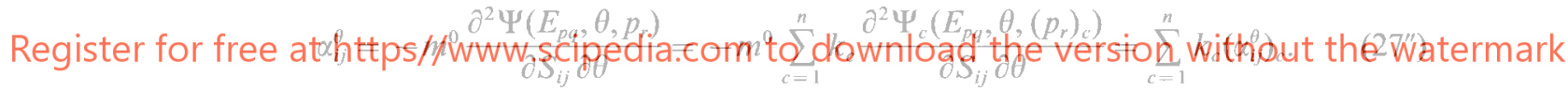

The stress-strain relationship is derived from the strain compatibility condition between substances [eqn (22)] as:

$$
\left(E_{i j}\right)_{c}=E_{i j}=\underbrace{\left(\mathscr{C}_{i j k l}^{\mathrm{S}-1}\left(\beta_{s}, \theta\right)\right)_{c}\left(S_{k l}\right)_{c}}_{\left(E_{i j}^{\mathrm{e}}\right)_{c}}+\left(E_{i j}^{\mathrm{p}}\right)_{c}+\left(\alpha_{i j}^{\theta}\right)_{c}\left(\theta-\theta_{0}\right) .
$$

The secant constitutive equation for the whole composite material (25) is rewritten as:

$$
\left.S_{i j}=\sum_{c=1}^{n} k_{c}\left(S_{i j}\right)_{c}=\sum_{c=1}^{n} k_{c}\left(\mathscr{C}_{i j k l}^{\mathrm{s}}\left(\beta_{s}, \theta\right)\right)_{c}\left(E_{k l}^{\mathrm{e}}\right)_{c}=\mathscr{C}_{i j k l}^{\mathrm{s}}\left(\beta_{s}, \theta\right) E_{k l}^{\mathrm{e}}\right]
$$

where the elastic strain for each compounding can be expressed as: $\left(E_{i j}^{\mathrm{e}}\right)_{c}=$ $E_{i j}-\left(E_{i j}^{\mathrm{p}}\right)_{c}-\left(\alpha_{i j}^{\theta}\right)_{c}\left(\theta-\theta_{0}\right)$; and for the composite as: $E_{i j}^{\mathrm{e}}=E_{i j}-E_{i j}^{\mathrm{p}}-\alpha_{i j}^{\theta}\left(\theta-\theta_{0}\right)$. From the last two equalities of eqn (29) and taking into account eqns (22) and (27'), it is possible to write the total plastic strain for the composite material. Thus,

$$
\begin{aligned}
S_{i j} & =\sum_{c=1}^{n} k_{c}\left(\mathscr{C}_{i j k l}^{\mathrm{S}}\left(\beta_{s}, \theta\right)\right)_{c}\left(E_{k l}^{\mathrm{e}}\right)_{c} \\
& =\sum_{c=1}^{n} k_{c}\left(\mathscr{C}_{i j k l}^{\mathrm{S}}\left(\beta_{s}, \theta\right)\right)_{c} E_{k l}-\sum_{c=1}^{n} k_{c}\left(\mathscr{C}_{i j k l}^{\mathrm{S}}\left(\beta_{s}, \theta\right)\right)_{c}\left(E_{k l}^{\mathrm{p}}\right)_{c}
\end{aligned}
$$




$$
-\sum_{c=1}^{n} k_{c}\left(\mathscr{C}_{i j k l}^{\mathrm{S}}\left(\beta_{s}, \theta\right)\right)_{c}\left(\alpha_{i j}^{\theta}\right)_{c}\left(\theta-\theta_{0}\right)
$$

and also from eqn (29) :

$$
\begin{aligned}
S_{i j} & =\mathscr{C}_{i j k l}^{\mathrm{s}}\left(\beta_{s}, \theta\right) E_{k l}^{\mathrm{e}} \\
& =\mathscr{C}_{i j k l}^{\mathrm{s}}\left(\beta_{s}, \theta\right) E_{k l}-\mathscr{C}_{i j k l}^{\mathrm{s}}\left(\beta_{s}, \theta\right) E_{k l}^{\mathrm{p}}-\mathscr{C}_{i j k l}^{\mathrm{s}}\left(\beta_{s}, \theta\right) \alpha_{i j}^{\theta}\left(\theta-\theta_{0}\right) .
\end{aligned}
$$

Equaling the right hand side of the last two equations, gives the plastic strain for the whole composite material:

$$
E_{i j}^{\mathrm{p}}=\mathscr{C}_{i j p q}^{\mathrm{S}-1}\left(\beta_{s}, \theta\right)\left\{\sum_{c=1}^{n} k_{c}\left(\mathscr{C}_{p q r s}^{\mathrm{S}}\left(\beta_{s}, \theta\right)\right)_{c}\left[\left(E_{r s}^{\mathrm{p}}\right)_{c}+\left(\alpha_{r s}^{\theta}\right)_{c}\left(\theta-\theta_{0}\right)\right]\right\}-\alpha_{i j}^{\theta}\left(\theta-\theta_{0}\right)
$$

with :

$$
\left(E_{i j}^{\mathrm{p}}\right)_{c}=\int_{0}^{t}\left(\dot{E}_{i j}^{\mathrm{p}}\right)_{c} \mathrm{~d} t, \text { and }\left(\dot{E}_{i j}^{\mathrm{p}}\right)_{c}=(\dot{\lambda})_{c} \frac{\partial\left(\mathscr{G}^{\mathrm{S}}\left(S_{r s}, \theta\right)\right)_{c}}{\partial\left(S_{i j}\right)_{c}}
$$

In the derivation of eqn (30) use of the following relationship obtained from eqns (22) and

(27) has been made
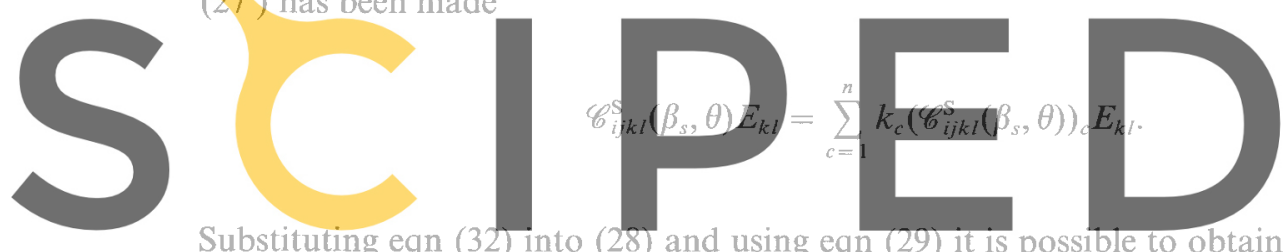

Substituting eqn
for each phase as

\section{Register for free at https/

$$
\left(S_{i j}\right)_{c}=\left(\mathscr{U}_{i j p q}^{\mathrm{S}}\left(\beta_{s}, \theta\right)\right)_{c}\left\{\mathscr{Q}_{p q k l}^{\mathrm{S}-1}\left(\beta_{s}, 0\right)\left[\sum_{c=1}^{n} k_{c}\left(\mathscr{Q}_{k l r s}^{\mathrm{S}}\left(\beta_{s}, \theta\right)\right)_{c} E_{r s}\right]-\left(E_{p q}^{\mathrm{p}}\right)_{c}-\left(\alpha_{p q}^{0}\right)_{c}\left(\theta-\theta_{0}\right)\right\} .
$$

Equation (34) gives the stress distribution for each compounding substance of the multiphase composite.

\section{NUMERICAL IMPLEMENTATION OF THE MULTIPHASE CONSTITUTIVE MODEL}

Appendix 1 presents a schematic view of the algorithm to implement the multiphase plastic-damage model into a general non-linear finite element solution scheme.

\section{EXAMPLES}

The previous general theory will be applied to three relatively simple examples to show the applicability and potential of the present model.

\subsection{Modelling of elastic behaviour of a fibre composite material}

This trivial example is presented to show the capability of the elastic part of the present model to reproduce the elastic tension behaviour of the longitudinal fibres in a composite material. 


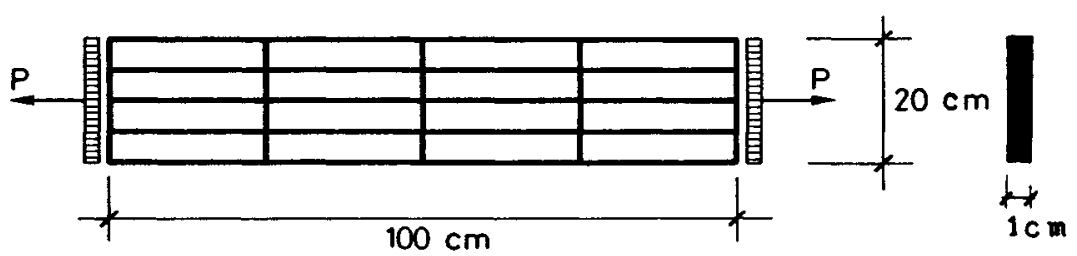

Fig. 2. Uniaxially loaded specimen. Geometry, boundary conditions, loading and finite element mesh.

Table 1 shows the variation of the load ratio $P_{\mathrm{F}} / P_{\mathrm{C}}$ for the tension specimen test, carried by the longitudinal fibres and the composite, vs the Young's modulus ratio $E_{\mathrm{F}} / E_{\mathrm{C}}$, for several values of the fraction volume of fibres $k_{\mathrm{F}}$. Results are in total agreement with those obtained by Jayatilaka (1979) using a simple composite model based on the assumption of full compatibility between elastic fibres and matrix.

\subsection{Uniaxially loaded specimen}

The model has also been tested in the analysis of a plane rectangular specimen, under axial loading acting as shown in Fig. 2. Plane stress conditions have been assumed. The geometry has been discretized using a simple mesh of 16 standard four-node quadrilateral elements. The base compounding materials are steel, aluminium and brass. An homogeneous distribution has been assumed with the respective participation percentages as shown in Table 2. Also in the same table, the corresponding properties for each isotropic base material are detailed: $E$ and $v$ are Young and Poisson modulus, $f^{\text {Comp }}$ is the elastic limit of compression strength, $H$ is the slope of the hardening function $c\left(\kappa^{\mathrm{p}}\right)$ and $k_{c}$ is the volume fraction of the " $q^{\text {th }}$ " substance. The three compounding materials are considered under associated plastic behaviour without damage, using Von-Mises yield functions. The maximum dissipation energy $G_{\mathrm{f}}$ for each compounding is considered unlimited.

Numerical results for the stress field in the composite are shown in Fig. 3 where the theoretical results are also plotted. Also, Fig. 3 shows the behaviour for each single compounding phase. Good agreement between the numerical and theoretical results is obtained.

The behaviour of this ideal bulk composite has many important aspects to remark. The overall composite behaviour (curve d of Fig. 3) remains in the elastic range until point 1. Then a slight plastification due to the tension-compression stresses acting on the brass occurs (curve c). This stress state induces a small plastification in the brass (point 2 of curve c) and also indirectly on the total composite (point 1 of curve d). The biaxial stress state in each compound results from the Poisson expansion effect on the other two compounds.

Brass (curve c) reaches the maximum stress (point 3) for strains of $10^{-3}$ while steel just then reaches its plastification state (point 6 of curve a). At the same time a small plastification initiates in the aluminium (point 4 of curve b). The overall composite response at this instant (curve d) undergoes a slope change (point 5-8). This is mainly due to the strong steel contribution (point 6-9). In the aluminium compounding (curve b), this slope change is produced at point 7 and this is followed by a new slope change in the overall composite response (point 8 of curve d) and on the steel compounding (point 9 of curve a) too.

Table 1. Fraction of fibres load $P_{\text {Fibres }} / P_{\text {Composite }}$

\begin{tabular}{rccc}
\hline$E_{\mathrm{F}} / E_{\mathrm{C}}$ & $P_{\mathrm{F}} /\left.P_{\mathrm{C}}\right|_{k_{\mathrm{F}}=0.1}$ & $P_{\mathrm{F}} /\left.P_{\mathrm{C}}\right|_{k_{\mathrm{F}}=0.2}$ & $P_{\mathrm{F}} /\left.P_{\mathrm{C}}\right|_{k_{\mathrm{F}}=0.4}$ \\
\hline 0.50 & 5.26315 & 11.11111 & 25.00000 \\
1.00 & 10.00000 & 20.00000 & 40.00000 \\
10.00 & 52.63157 & 71.42857 & 86.95650 \\
40.00 & 81.63265 & 90.90909 & 96.38554 \\
60.00 & 86.95652 & 93.75000 & 97.56097 \\
\hline
\end{tabular}




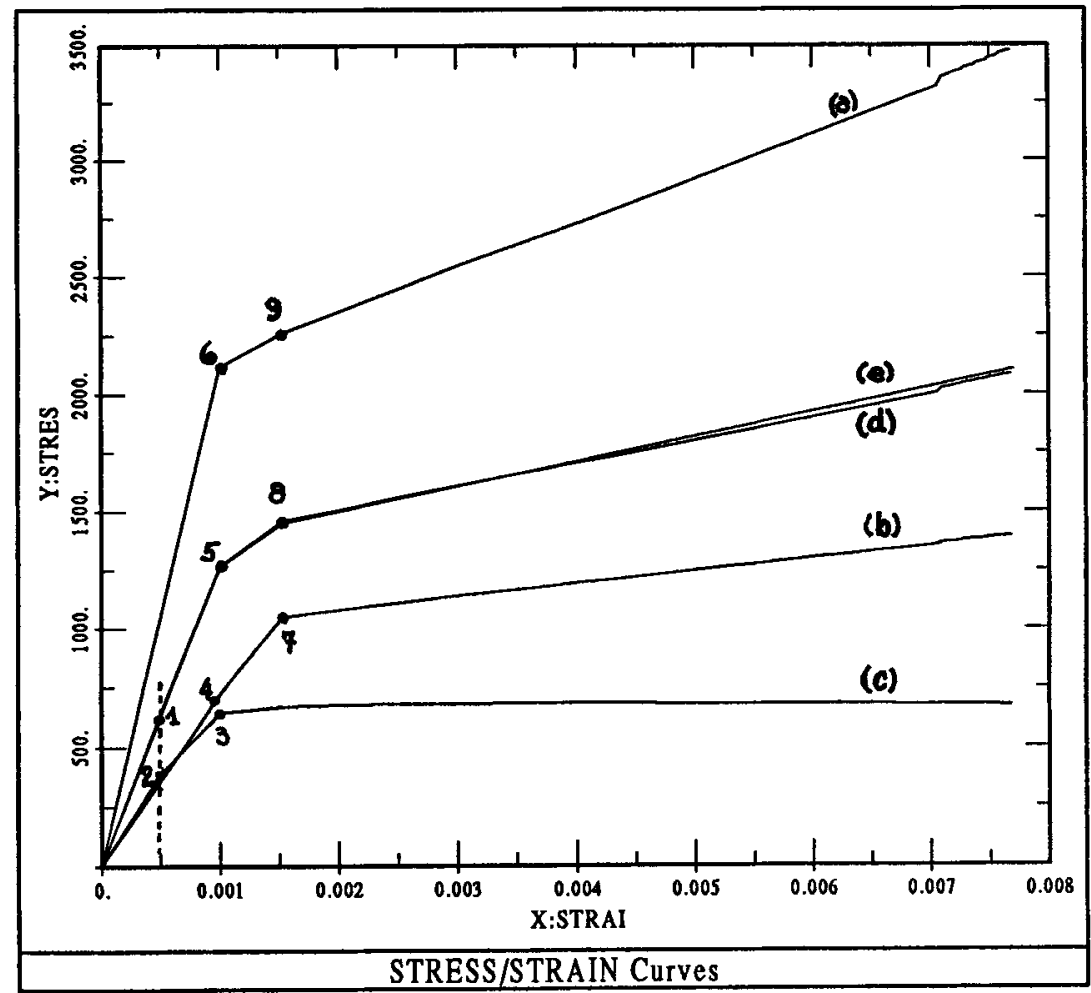

Fig. 3. Strain-stress curves at the centre of the sample for the : (a) steel, (b) aluminium, (c) brass, (d) numerical results, (e) theoretical results.

Table 2. Properties of compounding materials

\begin{tabular}{|c|c|c|c|c|c|}
\hline Component & $\begin{array}{c}E \\
{\left[\frac{\mathrm{kp}}{\mathrm{cm}^{2}}\right]}\end{array}$ & $v$ & $\begin{array}{l}f^{\text {Comp. }} \\
{\left[\frac{\mathrm{kp}}{\mathrm{cm}^{2}}\right]}\end{array}$ & $\begin{array}{c}H \\
{\left[\frac{\mathrm{kp}}{\mathrm{cm}^{2}}\right]}\end{array}$ & $\begin{array}{c}\text { Vol. fract. } \\
k_{c}[\%]\end{array}$ \\
\hline Steel & $2.100 \mathrm{E} 6$ & 0.30 & 2100.0 & $2.1 \mathrm{E} 5$ & 40.0 \\
\hline Aluminium & $0.725 \mathrm{E} 6$ & 0.25 & 1100.0 & $0.5 \mathrm{E} 5$ & 40.0 \\
\hline Brass & $0.800 \mathrm{E} 6$ & 0.20 & 650.0 & 0.0 & 20.0 \\
\hline
\end{tabular}

This example shows the capability of the present model to simulate complex bulk composite behaviour, as well the individual response of each compounding.

\subsection{Fracture test for a composite material}

This example has been oriented to show the capability of the present theory to model fracture phenomena in composites. A plane rectangular specimen is subjected to an imposed displacement acting as shown in Fig. 4. Plane stress conditions have been assumed. The geometry has been discretized using a mesh of 16 bilinear quadrilaterals as shown in the figure. The type and combination of isotropic materials are the same as those reported in

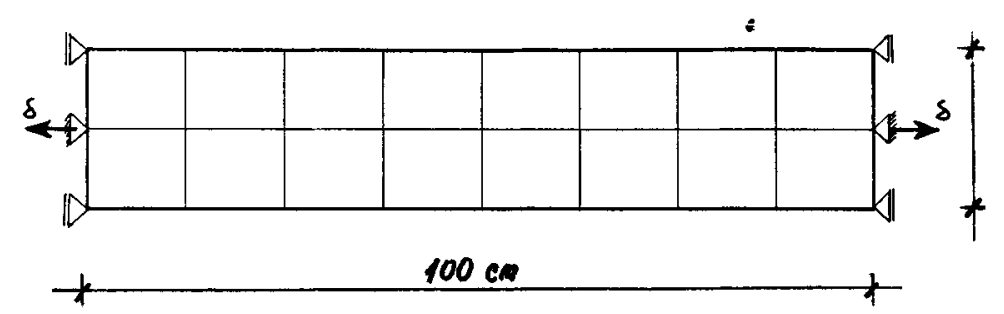

Fig. 4. Test specimen. Geometry, boundary conditions, loading and finite element mesh. 


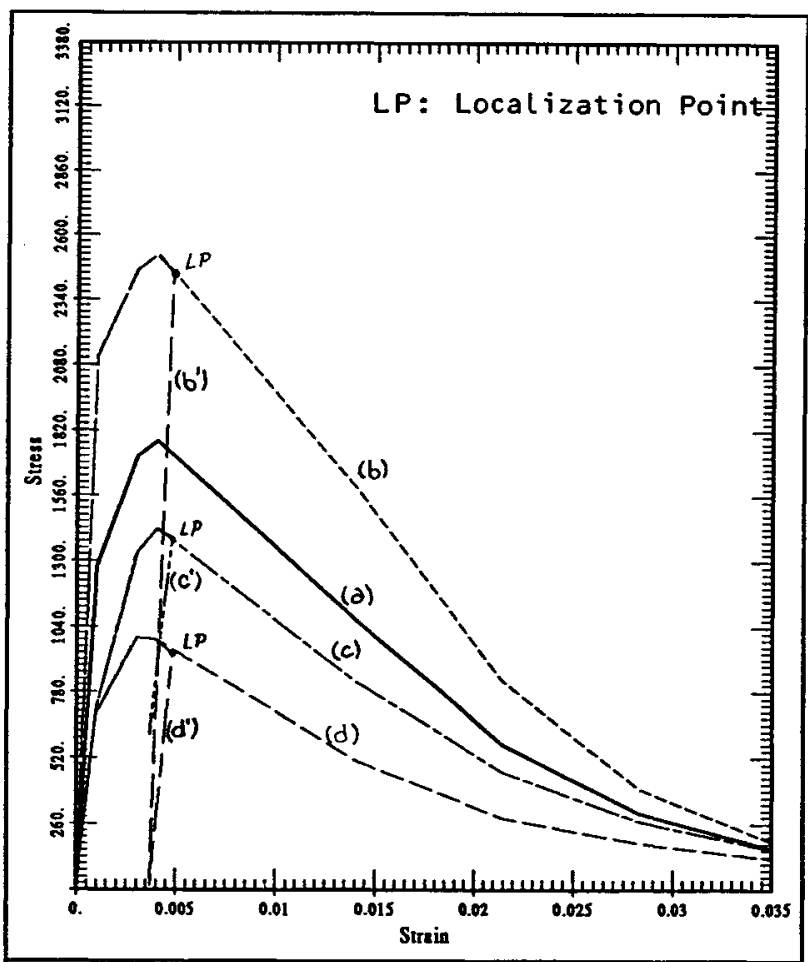

Fig. 5. Stress-strain curves : ${ }^{*}$ At the centre of the sample for the composite material (curve a), steel (curve b), aluminium (curve c) and brass (curve d). ${ }^{*} A t$ the ends of the sample for the steel material (curve $b^{\prime}$ ), aluminium (curve $c^{\prime}$ ) and brass (curve $d^{\prime}$ ).

Table 3. The three compounding materials, as in the previous example, are considered under plastic behaviour without damage, using a Von-Mises yield and plastic potential function. The maximum dissipation energy $G_{\mathrm{f}}$ for each compounding is limited to the values reported in Table 3 . The $c\left(\kappa^{\mathrm{p}}\right)$ stress-strain hardening evolution curve for each compounding is taken to be quadratic until the peak value $f_{\text {Peak }}^{\text {Comp }}, E_{\text {Peak }}^{\text {Comp }}$, and then cubic until the zero strength point.

For each of the three compounding materials the main difference is the response beyond the peak stress showing strain-softening behaviour. Figure 5 displays the stressstrain curve for the composite and the different compounding materials. For the composite (curve a) the stress peak is reached at a value of $S=1768.0 \mathrm{kp} / \mathrm{cm}^{2}$. Figure 6 shows a detail of the unloading history of the points located at the sample end zone.

Figure 7 shows the load-displacement curve representing the overall composite behaviour. The peak load is reached for $P=35500.0 \mathrm{kp}$ and $\delta=0.4 \mathrm{~cm}$.

Figure $8 \mathrm{a}$ displays the deformed mesh showing the strong strain localization effect at the centre. Also, note in Fig. 8 b the high concentration of plastic strain. This can be taken as a measure of the intensity of the micro-fracture process in the sample (Oller, 1988; Lubliner et al., 1989).

Table 3. Properties of compounding materials

\begin{tabular}{|c|c|c|c|c|c|c|c|}
\hline Compon. & $\begin{array}{c}E \\
{\left[\frac{\mathrm{kp}}{\mathrm{cm}^{2}}\right]}\end{array}$ & $v$ & $\begin{array}{l}f^{\text {Comp. }} \\
{\left[\frac{\mathrm{kp}}{\mathrm{cm}^{2}}\right]}\end{array}$ & $\begin{array}{c}G_{\mathrm{f}} \\
{\left[\frac{\mathrm{kp}}{\mathrm{cm}}\right]}\end{array}$ & $\begin{array}{l}f^{\text {Comp. }} \\
{\left[\frac{\mathrm{kp}}{\mathrm{cm}^{2}}\right]^{\text {Peak }}}\end{array}$ & $E_{\text {Peak }}^{\text {Comp. }}$ & $\begin{array}{c}\text { Vol. fract. } \\
k_{\text {c }}[\%]\end{array}$ \\
\hline Steel & $2.100 \mathrm{E} 6$ & 0.30 & 2100.0 & 500.0 & 2500.0 & 0.004 & 40.0 \\
\hline Aluminium & $0.725 \mathrm{E} 6$ & 0.25 & 1100.0 & 300.0 & 1500.0 & 0.004 & 40.0 \\
\hline Brass & $0.800 \mathrm{E} 6$ & 0.20 & 650.0 & 200.0 & 1000.0 & 0.003 & 20.0 \\
\hline
\end{tabular}




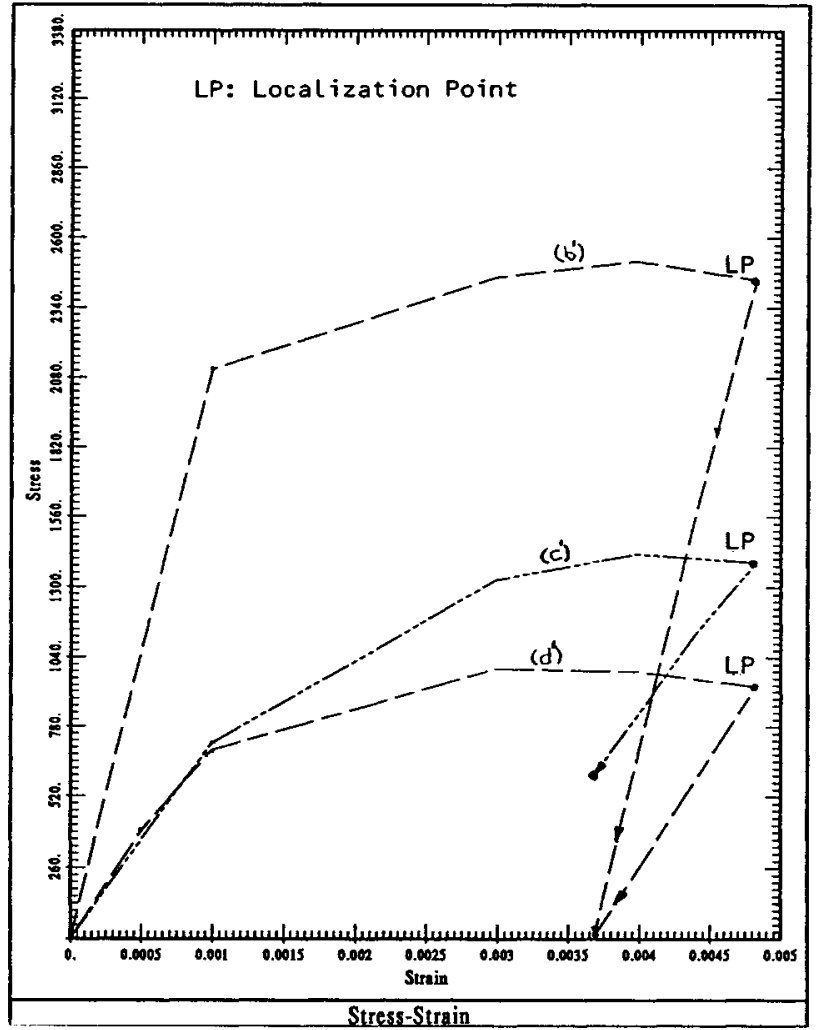

Fig. 6. Detail of the stress-strain curves at the sample ends for the steel (curve $b^{\prime}$ ), aluminium (curve $\mathrm{c}^{\prime}$ ) and brass (curve $\mathrm{d}^{\prime}$ ).

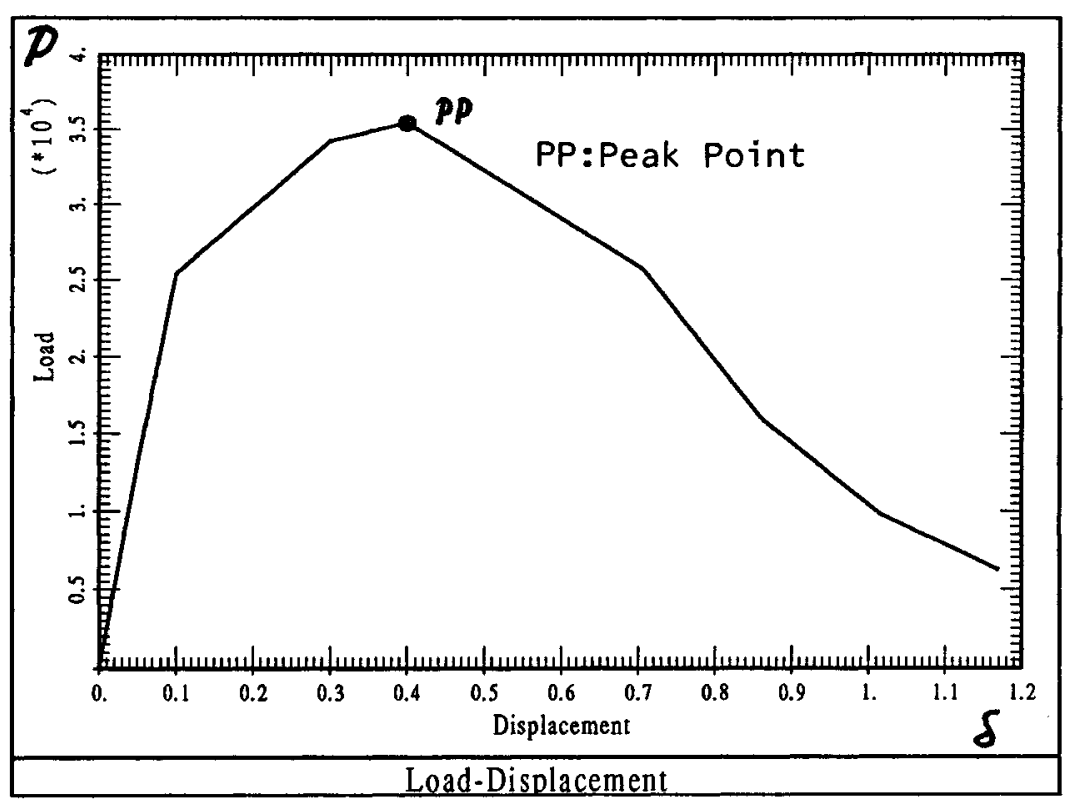

Fig. 7. Load-displacement response for the composite material. 
Malvern, L. (1969). Introduction to the Mechanics of Continuous Medium. Prentice Hall, U.S.A.

Obraztsov, I. F. and Vasilev, V. V. (1982). Mechanics of Composites. MIR Publishers, Moscow.

Oliver, J., Cervera, M., Oller, S. and Lubliner, J. (1990). Isotropic damage models and smeared crack analysis of concrete. SCI-C 1990, Second Int. Conf. on Computer Aided Design of Concrete Structure, Zell am See, Austria, pp. 945-957.

Oller, S. (1988). Un modelo de daño continuo para materiales friccionales. Ph.D. Thesis, Escuela Tecnica Superior de Ingenieros de Caminos Canales y Puertos de Barcelona, España.

Oller, S. (1989). Nuevos Materiales Estructurales, Cerámicos en Ingeniería. Centro Internacional de Métodos Numéricos en Ingeniería, Barcelona, España.

Oller, S., Onate, E., Oliver, J. and Lubliner, J. (1990). Finite element non-linear analysis of concrete structures using a plastic-damage model. Engng Fracture Mech. 35 (1/2/3) 219-231.

Oller, S., Botello, S., Miquel, J. and Oñate, E. (1995). An anisotropic elasto-plastic model based on an isotropic formulation. Int. J. Computer-Engng Computation 12, 245-262.

Oñate, E., Oller, S., Oliver, J. and Lubliner, J. (1988). A constitutive model of concrete based on the incremental theory of plasticity. Engng Computations 5, 4, 309-319.

Oñate, E., Oller, S., Botello, S. and Miquel, J. (1991). Metodos avanzados de calculo de estructuras de materiales compuestos. Ed. C.I.M.N.E., Nro. 11, Barcelona, España.

Ortiz, M. and Popov, E. P. (1982). Plain Concrete as a Composite Material. No. 1 pp. 139-150. Mechanics of Materials, North Holland.

Ortiz, M. and Popov, E. P. (1982). A physical model for the inelasticity of concrete. Proc. Roy. Soc. Lond. A 383, $101-125$.

Pickett, A. K., Ruckert, J., Ulrich, D. and Haug, E. (1989). Material damage law suitable for crashworthiness investigation of random and directional fibre composite material XVII International Finite Element Congress, Baden-Baden, Germany.

Rouvray, A. and Haug, E. (1989). Failure of Brittle and Composite Materials by Numerical Methods (Chapter 7)-Structural Failure. John Willey and Sons.

Simo, J. and Ju, J. (1987). Strain and stress-based continuum damage models I. Formulation. Int. J. Solids Structures 23(7) 821-840.

Trusdell, C. and Toupin, R. (1960). The Classical Field Theories. (Edited by S. Flugge), Handbuch der Physik III/I, Springer, Berlin.

Zienkiewicz, O. C. and Taylor, R. L. (1989). The Finite Element Method-Basic Formulation and Linear Problem. Vol. 1, Mac-Graw Hill.

\section{APPENDIX}

Non-linear finite element solution scheme for the multiphase composite model

(1) Define the constitutive matrix and the participation of the different phases:

$$
\begin{aligned}
& { }^{n}\left(\boldsymbol{C}^{\mathrm{S}}\right)_{c}^{i-1}=\mathscr{L}^{n}(\beta)_{c}^{i-1}{ }^{1}\left(\boldsymbol{C}^{0}\right)_{c}^{0} \\
& { }^{n}\left(\boldsymbol{C}^{\mathbf{T}}\right)^{i-1}={ }^{n}\left(\boldsymbol{C}^{\mathrm{S}}\right)^{i-1}=\sum_{c} k_{c} \cdot{ }^{n}\left(\boldsymbol{C}^{\mathrm{S}}\right)_{c}^{i-1}
\end{aligned}
$$

$\Rightarrow$ LOOP OVER LOAD INCREMENTS : $n^{\text {th }}$ increment,

$\Rightarrow$ LOOP OVER CONVERGENCE ITERATIONS $: i^{\text {th }}$ iteration.

(2) Compute the tangent stiffness matrix for each element and the structure :

$$
\begin{aligned}
{ }^{n}\left(\boldsymbol{K}^{(e)}\right)^{i-1} & =\int_{\boldsymbol{V}} \boldsymbol{B}:{ }^{n}\left(\boldsymbol{C}^{\mathbf{T}}\right)^{i-1}: \boldsymbol{B} \mathrm{d} \boldsymbol{V} \\
{ }^{n}(\boldsymbol{K})^{i-1} & =\mathbf{A}_{e=1}^{n e t}{ }^{n}\left(\boldsymbol{K}^{(e)}\right)^{i-1} .
\end{aligned}
$$

(3) Compute the nodal displacements increments and the strains in the composite:

$$
\begin{aligned}
{ }^{n}(\delta U)^{i} & ={ }^{n}\left(\boldsymbol{K}^{-1}\right)^{i-1 \cdot n}\left(\boldsymbol{F}_{\text {resid }}\right)^{i-1} \\
{ }^{n}(\Delta U)^{i} & ={ }^{n}(\Delta U)^{i-1}+{ }^{n}(\delta U)^{i} \\
{ }^{n}(U)^{i} & ={ }^{n-1}(U)+{ }^{n}(\Delta U)^{i} \\
{ }^{n}(E)^{i} & =\nabla_{s}{ }^{n}(U)^{i} \\
{ }^{n}(\Delta E)^{i} & ={ }^{n}(E)^{i}-{ }^{n-1}(E)
\end{aligned}
$$

$\Rightarrow$ LOOP OVER THE $c$ compounding substances: 
a)

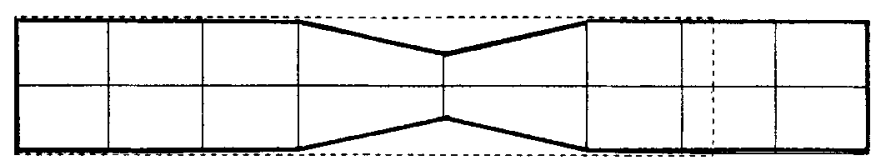

FEMGENFEMVIEW 1.0578.8 UNIVERSTTAT DB CATALUNYA

MODEL: PLCRAC

PLSTR: TRACCION US
STER: 103 LOAD: 11.1

PRNC STRESS ALL
RESULTS WERE CALCULATED

b)

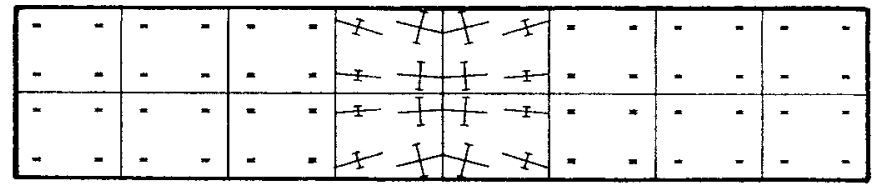

Fig. 8. (a) Mesh deformation at the end of the numerical test. (b) Principal plastic deformation vectors at the end of the numerical test.

\section{CONCLUDING REMARKS}

The theoretical framework presented combines basic concepts from multiphase mixing theory with an elasto-plastic damage base constitutive model. Such a framework provides a powerful tool for modelling the behaviour of composite materials. Moreover, the constitutive law presented can simulate the fracture behaviour of each compound, in addition to that of the overall composite.

In the present work isotropic material conditions for each compound have been assumed, although overall anisotropy effects can be simply included (see Oller et al., 1995). Also, induced anisotropic behaviour is intrinsic in the constitutive law of each compound. This allows modelling of localization phenomena typical of softening materials. Extensions of the model to treat layer composite materials are in development by the authors.

\section{REFERENCES}

Bažant, Z. and Kim, S. (1979). Plastic fracturing theory for concrete. J. Engng Mech. Div. ASCE 105, (EM3) 407-428.

Garcia Garino, C. and Oliver, J. (1992). A numerical model for elastoplastic large strain problems. Fundamentals and applications. In Computational Plasticity (Edited by R. Owen, E. Oñate and E. Hinton), Vol. 1, pp. 117129. Pineridge Press-CIMNE.

Green, A. and Naghdi, P. (1965). A dynamical theory of interacting continua. Int. J. Engng Sci. 3, 231.

Green, A. and Naghdi, P. (1964). A general theory of an elastic-plastic continuum. Arch. Rational Mech. Anal. 18, 19-281.

Jayatilaka, A. (1979). Fracture of Engineering Brittle Material. Applied science LTD, England.

Kachanov, L. (1958). Time of the rupture process under creep conditions. Otd. Tech. Nauk. (8) 26-31.

Lubliner, J. (1985). Thermomechanics of Deformable Bodies. (Edited by Department of Civil Engineering University of California, Berkeley, U.S.A.).

Lubliner, J. (1986). Normality rules in large-deformation plasticity. Mechanics of Materials (5) 29-34.

Lubliner, J. (1984). A maximum-dissipation principle in generalized plasticity. Acta Mech. (52) 225-237.

Lubliner, J. (1974). A simple theory of plasticity. Int. J. Solids Structures (10) 313-319.

Lubliner, J. (1972). On thermodynamics foundations of non-linear solid mechanics. Int. J. non-linear Mech. (7) $237-254$.

Lubliner, J. (1990). Plasticity Theory. Macmillan, U.S.A.

Lubliner, J., Oliver, J., Oller, S. and Oñate, E. (1989). A plastic damage model for non linear analysis of concrete. Int. J. Solids Structures 25, (3) 299-326. 
Integration of constitutive model

(4) Compute the predicted non-damaged stresses for each compound:

$$
\begin{aligned}
\bullet{ }^{n}\left(\boldsymbol{S}^{0}\right)_{c}^{i} & ={ }^{1}\left(\boldsymbol{C}^{0}\right)^{0}:{ }^{n}(\boldsymbol{E})^{i} \\
{ }^{n}\left(\boldsymbol{C}^{\prime}\right)_{c}^{i} & ={ }^{n}\left(\boldsymbol{C}^{\mathrm{S}}\right)_{i}^{i} .
\end{aligned}
$$

(5) Integrate the damage constitutive equation for each compound (Euler Backward Scheme) :

$\Rightarrow$ LOOP OVER INNER CONVERGENCE ITERATIONS : $j^{\text {th }}$ iteration :

$$
\begin{aligned}
& \text { for }: j=1 \Rightarrow^{n}(S)_{c}^{i, 0}={ }^{n}\left(S^{\circ}\right)_{c}^{i} \\
& { }^{n}(\boldsymbol{S})_{c}^{i, j}=\mathscr{L}^{n}(\beta)_{c}^{i, j n}(\boldsymbol{S})_{c}^{i, j-1} \\
& { }^{n}(S)_{c}^{i, j}=S\left({ }^{n}(S)_{c}^{i, j}\right) \\
& \text { Is: } \mathscr{G}_{c}^{D}\left(S_{c}, \beta^{r}\right){ }_{S_{i}^{j, j-1}} \leqslant 0 \Rightarrow \text { (no damage) GOTO } 7 \text { (damage) } \\
& { }^{n}\left(\Delta \beta^{r}\right)_{c}^{i, j}=(\Delta \mu)^{j \cdot n}\left(\frac{\partial \mathscr{G}_{c}^{D}}{\partial S_{c}}\right)^{j} \\
& { }^{n}\left(\beta^{r}\right)_{c}^{i, j}={ }^{n}\left(\beta^{r}\right)_{c}^{i, j-1}+{ }^{n}(\Delta \beta r)_{c}^{i, j} \\
& j=j+1 \text { Go back to }
\end{aligned}
$$

(6) Compute the damage tangent constitutive matrix for each compound

$$
{ }^{n}\left(\boldsymbol{C}^{e}\right)_{c}^{i}=\mathscr{L}^{n}(\beta)_{c}^{i, j}\left(C^{0}\right)_{c}^{0}+\frac{(T)_{c}^{i, j}}{\mathscr{L}^{n}(\beta)_{c}^{i, j}} \otimes{ }^{n}(S)_{c}^{i, j}
$$

(7) Compute the predicted stress for each plastic compound:

$$
\begin{aligned}
& { }^{n}(\boldsymbol{S})_{c}^{i}={ }^{n}(\boldsymbol{S})_{c}^{i, j} \\
& { }^{n}\left(\boldsymbol{S}^{*}\right)_{c}^{i}={ }^{n}(\boldsymbol{S})_{c}^{i}-\mathscr{L}^{n}(\beta)_{c}^{i, j}{ }^{1}\left(\boldsymbol{C}^{0}\right)_{c}^{0}:^{n-1}\left(\boldsymbol{E}^{p}\right)_{c} .
\end{aligned}
$$

(8) Integrate the plastic constitutive equation for each compound (Euler Backward Scheme):

$\Rightarrow$ LOOP OVER INNER CONVERGENCE ITERATIONS $: \boldsymbol{k}^{\text {th }}$ iteration :

$$
\begin{aligned}
& \text { for } k=1:{ }^{n}(S)_{c}^{i_{c}, 0}={ }^{n}\left(S^{*}\right)_{c}^{i}, \quad{ }^{n}\left(\Delta \boldsymbol{E}^{p}\right)_{c}^{i_{0}, 0}=0 \\
& \operatorname{PAp}^{n}(\boldsymbol{S})_{c}^{i, k}={ }^{n}(\boldsymbol{S})_{c}^{i, k-1}-{ }^{1}\left(\boldsymbol{C}^{S}\right)^{0}:^{n}\left(\Delta \boldsymbol{E}^{p}\right)^{i, k-1} \\
& \text { Is : } \mathscr{F}_{c}^{S}\left(\boldsymbol{S}_{c}, \alpha^{m}\right)_{n_{s}^{t k}} s_{t} \leqslant 0 \Rightarrow \text { (no yielding) GOTO } 10 \\
& \text { (yielding) } \\
& \Downarrow \\
& { }^{n}\left(\Delta \boldsymbol{E}^{p}\right)_{c}^{i, k}=(\Delta \lambda)^{k} \cdot n\left(\frac{\partial \mathscr{G}_{c}^{S}}{\partial \boldsymbol{S}_{c}}\right)^{k} S_{S^{i . k}} \\
& { }^{n}\left(\boldsymbol{E}^{p}\right)_{c}^{i, k}={ }^{n}\left(\boldsymbol{E}^{p}\right)_{c}^{i, k-1}+{ }^{n}\left(\Delta \boldsymbol{E}^{p}\right)_{c}^{i, k} \\
& { }^{n}\left(\Delta \alpha^{m}\right)_{c}^{i, k}=(\Delta \lambda)^{k} \cdot{ }^{n}\left(\boldsymbol{h}^{m}\right)_{c}^{i, k} \cdot{ }^{n}\left(\Delta \boldsymbol{E}^{p}\right)_{c}^{i, k} \\
& { }^{n}\left(\alpha^{m}\right)_{c}^{i, k}={ }^{n}\left(\alpha^{m}\right)_{i}^{i, k-1}+{ }^{n}\left(\Delta \alpha^{m}\right)_{c}^{i, k} \\
& k=k+1 \text { Go back to }
\end{aligned}
$$

(9) Compute the plastic tangent constitutive matrix for each phase:

$$
\begin{gathered}
{ }^{n}\left(\boldsymbol{C}^{e p}\right)_{c}^{i}=\left\{\boldsymbol{C}_{c}^{e}-\frac{\left(C^{S}: \frac{\partial \mathscr{G}^{S}}{\partial S}\right) \otimes\left(C^{e}: \frac{\partial \mathscr{F}^{S}}{\partial S}\right)}{-\Sigma_{m} \frac{\partial \mathscr{F}^{S}}{\partial \alpha^{m}}\left(\mathbf{h}_{S}^{m}\right): \frac{\partial \mathscr{G}^{S}}{\partial S}+\frac{\partial \mathscr{F}^{S}}{\partial S}: C^{s}: \frac{\partial \mathscr{G}^{S}}{\partial S}}\right\}^{n} S^{i}, c \\
c=c+1 \text { Go back to } \bullet .
\end{gathered}
$$


(10) Compute:

$$
\begin{aligned}
{ }^{n}(\boldsymbol{S})^{i} & =\sum_{c} k_{c} \cdot{ }^{n}(\boldsymbol{S})_{c}^{i} \\
{ }^{n}\left(\boldsymbol{C}^{T}\right)_{c}^{i} & =\left\{\begin{array}{l}
{ }^{n}\left(\boldsymbol{C}^{r}\right)^{i}, \text { without plasticity } \\
{ }^{n}\left(\boldsymbol{C}^{e n}\right)_{c}^{i}, \text { with plasticity }
\end{array}\right. \\
{ }^{n}\left(\boldsymbol{C}^{T}\right)^{i} & =\sum_{c} k_{c} \cdot{ }^{n}\left(\boldsymbol{C}^{T}\right)_{c}^{i} .
\end{aligned}
$$

(11) Compute the residual force vector and check convergence:

$$
\begin{gathered}
{ }_{n}^{n}\left(\boldsymbol{F}_{\text {resid }}^{(e)}\right)^{i}=\int_{V} \boldsymbol{B}:{ }^{n}(S)^{i} \mathrm{~d} V-\boldsymbol{F}_{\text {ext }} \\
{ }^{n}\left(F_{\text {resid }}\right)^{i}=\mathbf{A}_{e=1}^{n e l} I^{n}\left(\mathbf{F}_{\text {resid }}^{(e)}\right)^{i} \\
\text { Is }\left\|\mathbf{F}_{\text {resid }}\right\|>\varepsilon\left\|\mathbf{F}_{\text {ext }}\right\| ? \Rightarrow i=i+1 . \quad \text { Go back to } 4 . \\
\text { STOP }
\end{gathered}
$$

